\title{
Evaluation of Flexural Capacity of RC Elements Exposed to Fire
}

\author{
Sukhwinder Singh ${ }^{1}$ and Mustesin Ali Khan ${ }^{2}$ \\ ${ }^{1}$ Colonel, Indian Army, HQ CWE No 2, Tigris Road, Delhi-110010, India \\ ${ }^{2}$ Research Assistant Professor, Department of Building Services Engineering, The Hong Kong Polytechnic University, Hong Kong
}

*Corresponding author: Dr Mustesin Ali Khan, Research Assistant Professor, Department of Building Services Engineering, The Hong Kong Polytechnic University, Hong Kong.
Received Date: June 09, 2020

Published Date: July 27, 2020

\begin{abstract}
When Reinforced concrete flexural members of a structure are exposed to fire they tend to lose their original flexural capacity. It is important to assess the reduction in flexural capacity. This paper presents a simple numerical model for prediction of residual moment capacity of fire damaged RC flexural element after cooling to ambient temperature. The prediction of residual moment capacity of fire damaged RC element has been carried out by assessing the residual properties of fire affected concrete and steel. The proposed prediction model has been arrived at by comparing various constitutive models available in literature for the residual strength of steel rebar and concrete. A total of 9 fire damaged RC beams (tested after cooling) were selected from literature for this study. It is seen that the predicted results were then compared with the experimental results. The predicted results using this proposed model have better agreement with the experimental results as compared to those by existing methods.
\end{abstract}

Keywords: Fire Exposure; Residual Mechanical Properties of Steel rebar and concrete; Loss of Strength; Air cooling; Residual Moment Capacity; Residual Strength Constitutive Models

Notations

\begin{tabular}{|c|c|}
\hline Notation & Used for \\
\hline $\mathrm{A}_{\mathrm{st}}$ & Total area of tension reinforcement \\
\hline $\mathrm{a}$ & Distance between bottom surface of the effective cross-section to the centroid of the reinforcement \\
\hline $\mathrm{b}$ & Width of RC beam section at ambient temperature \\
\hline $\mathrm{b}_{\mathrm{fi}}$ & Width of fire reduced effective cross-section \\
\hline $\mathrm{c}$ & Clear cover \\
\hline $\mathrm{d}$ & Effective depth of RC beam section at ambient temperature \\
\hline $\mathrm{d}_{\mathrm{fi}}$ & Effective depth of the fire reduced effective cross-section \\
\hline $\mathrm{D}$ & Overall depth of RC beam section at ambient temperature \\
\hline $\mathrm{f}_{\mathrm{c}}$ & Cylindrical compressive strength of concrete at ambient temperature \\
\hline $\mathrm{f}_{\mathrm{cT}}$ & Residual cylindrical compressive strength of concrete after heating to elevated temperature T \\
\hline $\mathrm{f}^{\prime}{ }_{\mathrm{cT}}$ & Cylindrical compressive strength of concrete at elevated temperature $\mathrm{T}$ \\
\hline $\mathrm{f}_{\mathrm{y}}$ & Yield strength of tension reinforcement at ambient temperature \\
\hline
\end{tabular}




\begin{tabular}{|c|c|}
\hline $\mathrm{f}_{\mathrm{yT}}$ & Residual Yield strength of tension reinforcement after heating to elevated temperature $\mathrm{T}$ \\
\hline $\mathrm{f}_{\mathrm{u}}$ & Ultimate strength of tension reinforcement at ambient temperature \\
\hline $\mathrm{f}_{\mathrm{ut}}$ & Residual ultimate strength of tension reinforcement after heating to elevated temperature $\mathrm{T}$ \\
\hline $\mathrm{k}_{\mathrm{cT}}$ & Residual Strength reduction factor of concrete after heating to elevated temperature $\mathrm{T}$ \\
\hline $\mathrm{k}_{\mathrm{cTi}}$ & Residual Strength reduction factor of steel rebar after heating to elevated temperature $\mathrm{T}$ \\
\hline $\mathrm{k}_{\mathrm{sT}}$ & section elevated temperature $\mathrm{T}$ for $\mathrm{i}^{\text {th }}$ concrete layer in beam \\
\hline $\mathrm{l}$ & Span length for constant moment zone or distance between two-point loads \\
\hline $\mathrm{l}_{0}$ & Number of steel rebars \\
\hline $\mathrm{n}$ & Temperature in ${ }^{\circ} \mathrm{C}$ \\
\hline $\mathrm{T}$ & Furnace temperature in ${ }^{\circ} \mathrm{C}$ \\
\hline $\mathrm{T}_{\mathrm{f}}$ & Ratio between beam height and beam width \\
\hline $\mathrm{r}$ & Fire exposure time in hours \\
\hline $\mathrm{t}$ & Depth of neutral axis \\
\hline $\mathrm{Y}$ & Lever arm between the tension reinforcement and the concrete \\
\hline $\mathrm{Z}$ & Diameter of steel rebar \\
\hline$\phi$ &
\end{tabular}

\section{Introduction}

Fire leaves behind its impact on a structure. During a fire event different parts of a structure may get exposed to different level of temperatures which may cause partial damage or total collapse of the structure. Different parts of it may get exposed to different temperatures during or after fire exposure. This causes reduction in the strength and stiffness of both concrete and steel significantly and also affects their other physical properties. To safely use the structure post fire it is imperative to assess the residual moment capacity of the flexural members exposed to fire for carrying out the necessary retrofitting work in order to bring them back in service. The residual Moment capacity of any RC flexural member will depend on the residual strengths of its constituents i.e. concrete and reinforcing steel, which in turn depends upon the temperature reached during the fire exposure. From the study of various constitutive models of reduction in strength of concrete and steel rebar on exposure to high temperatures, it has emerged that concrete loses most of its strength post exposure to high temperatures. It is convenient to assume with fair accuracy that the tensile strength of concrete can be totally ignored for all practical purposes and the residual compressive strength can be predicted using the constitutive models available. Whereas in case of reinforcing steel most of the initial strength is regained after cooling and various models proposed for residual strength can be used. Most of the models predict fair amount of recovery of tensile strength post fire exposure. This paper presents a simple model for predicting the residual moment capacity of the fire exposed reinforced concrete flexural members. A comparison of the residual moment capacity predicted with this model and the existing models has also been carried out. 9 fire damaged RC beams [1-4] (tested after cooling) have been selected from literature for this study. The proposed model gives more realistic predictions closer to the experimental results as compared to any other model available.

\section{Temperature Profile Prediction}

In any RCC element, exposed to fire, the temperatures within a concrete element, including the steel rebar, continue to rise for a period after the maximum fire temperature has been reached. Before predicting the residual properties of the concrete and steel exposed to fire, it is necessary to predict correctly the temperature profile inside the fire exposed reinforced concrete member. In this paper, for the temperature profile prediction, Desai's [5] method has been adopted. Desai [5] adopted a simple equation to predict the temperature profiles of rectangular RC beams based on his own experimental results and those of some others [6,7]. The temperature $\mathrm{T}\left({ }^{\circ} \mathrm{C}\right)$ of a contour at a distance $\mathrm{x}$ (in $\mathrm{mm}$ ) from the fire-exposed surfaces of the beam was assumed to be influenced by the following factors:

a) $t$, the fire-exposure time (in min);

b) b, the width of beam cross-section (in mm); and

c) $r$, the ratio between beam height and beam width. Desai's [5] equation is as follows:

$$
T=\frac{D-A x+B x^{2}-C x^{3}}{r^{25}}
$$

Where,

$$
A=3.33\left[3+0.00033 t+\left(\frac{100-t}{b}\right)\right]
$$

$$
B=0.085
$$




$$
\begin{aligned}
& C=0.000221 \\
& D=475 r^{\frac{7}{12}}-\left(b-10 t^{3}\right)^{\frac{1}{-}}
\end{aligned}
$$

The applicability of above equation is limited to beams satisfying the following two conditions: $100 \mathrm{~mm}<\mathrm{b}<300 \mathrm{~mm}$ and $1<r<3$. If $r \leq 1.5$, then it is assumed that $r=1.5$ in the calculation.

\section{Constitutive Relationships for Material Properties After Fire Exposure}

To arrive at the best combination of residual strength constitutive models of concrete and reinforcing steel for prediction of the residual moment capacity of fire exposed structural members, a comparative study of various combinations of residual strength properties of the concrete and steel rebar has been carried out. A total of eight permutation and combinations with four residual constitutive models of concrete and two residual constitutive models of reinforcing steel has been carried out. The various models considered are discussed in succeeding paragraphs

\section{Constitutive Relationship for Residual Material} Properties of Concrete

Considerable amount of experimental investigations have been performed for determination of residual (after cooling) compressive strength of concrete after fire exposure by different researchers. In this study, Eurocode 4 [8], Chang et al. [9], Hsu et al. [10] and Xiaoyong et al. [11] models have been considered for prediction of residual compressive strength of concrete.

Eurocode 4 [8] Model: Residual material properties for thermally affected concrete after cooling suggested by Eurocode 4 (Annex C: EN 1994-1-2:2005) [8] has been explained here

$$
\begin{array}{rlrl}
\frac{f_{c T}}{f_{c}} & =K_{c T} & & ; 20^{\circ} C \leq T<100^{\circ} \mathrm{C} \\
& =1.0-0.235 * \frac{(T-100)}{200} & & ; 100^{\circ} \mathrm{C} \leq T<300^{\circ} \mathrm{C} \\
& =0.9 * k_{c T} & & ; T \geq 300^{\circ} \mathrm{C} \\
f_{c^{\prime} T} & =K_{c T} * f_{c} & & \\
K_{c T} & =\text { Strenghth reduction factor }
\end{array}
$$

\section{(Table 3.1: EN 1992-1-2:2004) [7]}

Chang et al. [9] Model: Chang et al. [9] model of residual compressive strength of concrete after fire exposure:

$$
\begin{aligned}
\frac{f_{c T}}{f_{c}} & =1.008+\frac{T}{450 * \ln (T / 5800)} \geq 0.0 & & ; 20^{\circ} C \leq T<800^{\circ} \mathrm{C} \quad \text { Or alternatively } \\
& =1.01-0.00055 T & & ; 20^{\circ} C \leq T<200^{\circ} \mathrm{C} \\
& =1.15-0.00125 T & & ; 200^{\circ} \mathrm{C} \leq T<800^{\circ} \mathrm{C}
\end{aligned}
$$

Hsu et al. (2006) [10] Model: Hsu et al. [10] model of residual compressive strength of concrete after fire exposure:

$$
\begin{aligned}
\frac{f_{c T}}{f_{c}} & =1-0.001 T & & ; 0^{\circ} \mathrm{C} \leq T<500^{\circ} \mathrm{C} \\
& =1.375-0.000175 T & & ; 500^{\circ} \mathrm{C} \leq T<700^{\circ} \mathrm{C} \\
& =0 & & ; 700^{\circ} \mathrm{C} \leq T
\end{aligned}
$$

Xiaoyong et al. (2011) [11] Model: Xiaoyong et al. [11] model of residual compressive strength of concrete after fire exposure:

$$
\begin{aligned}
\frac{f_{c T}}{f_{c}} & =-3.11\left(\frac{T}{1000}\right)^{2}+0.96\left(\frac{T}{1000}\right)+0.97 & & ; 20^{\circ} \mathrm{C} \leq T<400^{\circ} \mathrm{C} \\
& =-2.4\left(\frac{T}{1000}\right)+1.77 & & ; 400^{\circ} \mathrm{C} \leq T<600^{\circ} \mathrm{C}
\end{aligned}
$$

\section{Constitutive Relationship for Residual Material \\ Properties of Steel Rebar}

In this study, two constitutive models proposed by Tao et al. [12] and Topcu et al. 13] have been used for the evaluation of residual material properties of thermally affected steel rebar after cooling. Degradation of the material properties of steel rebar due to fire exposure was incorporated in the model by using temperature dependent reduction factors.

\section{Tao et al. (2013) [12] Model}

a) Residual yield strength of steel rebar after fire exposure is as below

$$
\begin{aligned}
\frac{f_{y T}}{f_{y}} & =1 & & ; T \leq 500^{\circ} \mathrm{C} \\
& =1-5.82 * 10^{-4}(T-500) & & ; T>500^{\circ} \mathrm{C}
\end{aligned}
$$

b) Ultimatestrengthofsteelrebarafterfire exposureisasbelow

$$
\begin{array}{rlrl}
\frac{f_{u T}}{f_{u}} & =1 & & ; T \leq 500^{\circ} \mathrm{C} \\
& =1-4.85 * 10^{-4}(T-500) & ; T>500^{\circ} \mathrm{C}
\end{array}
$$

\section{Topcu et al. (2008) [13] Model}

a) Residual yield strength of ribbed steel bars after fire exposure:

$\frac{f_{y T}}{f_{y}}=\left(\frac{1}{505.28}\right)\left(-0.0006 T^{2}+0.0625 T+504.27\right) ; 20^{\circ} \mathrm{C} \leq T \leq 950^{\circ} \mathrm{C}$

b) Residualyield strength of plainsteelbarsafterfireexposure: $\frac{f_{y T}}{f_{y}}=\left(\frac{1}{310.722}\right)\left(-0.0001 T^{2}+0.0016 T+310.65\right) ; 20^{\circ} C \leq T \leq 950^{\circ} C$

\section{Conventional Residual Moment Capacity Prediction Methods}

After fire exposure and subsequent cooling to ambient temperature, the residual moment capacity of the fire damaged RC elements can be predicted conventionally by following methods:

a) $500^{\circ} \mathrm{C}$ isotherm method.

b) Modified $500^{\circ} \mathrm{C}$ isotherm method.

c) Method of slices.

As per Eurocode 2 (Annex B: EN 1992-1-2) [8], the residual moment capacity of fire damaged reinforced concrete beam after 
cooling can be calculated conventionally by making use of $500^{\circ} \mathrm{C}$ isotherm method and slice method. In $500^{\circ} \mathrm{C}$ isotherm method concrete lying outside of the $500^{\circ} \mathrm{C}$ isotherm line is assumed to have zero strength and that lying inside is assumed to have same compressive strength as original concrete. For modified $500^{\circ} \mathrm{C}$ isotherm method, similar prediction steps have also been adopted. This method is quite similar to $500^{\circ} \mathrm{C}$ isotherm method but with a modification that for concrete lying within $500^{\circ} \mathrm{C}$ isotherm it uses mean residual compressive strength of concrete $\left(\mathrm{f}_{\mathrm{cT}}\right)$ after fire exposure at temperature $\mathrm{T}$ in place of compressive strength of concrete at ambient temperature $\left(f_{c}\right)$ for the calculation of residual moment capacity of fire exposed RCC beam after cooling. In the method of slices, the heat affected cross-section is divided into a number of slices/parallel zones and the temperature is determined at mid-depth of each slice. According to the temperature of middepth of slices, residual compressive strength of concrete (by using Eurocode 4 [8] model) and residual modulus of elasticity of concrete of each zone is determined Various prediction methods given above require the effective area after fire exposure by calculating the reduced effective width $\left(b_{\mathrm{fi}}\right)$ and effective depth $\left(\mathrm{d}_{\mathrm{fi}}\right)$.

\section{Proposed 'Reduced Strength Method' for Calculation of Residual Moment Capacity}

\section{Principles}

a) The heat affected cross-section is divided into several slices/parallel zones and the temperature is determined at middepth of each slice.

b) The more the number of slices the better the results.

c) According to the temperature of mid-depth of slices, residual compressive strength of concrete (by using Eurocode 4 [8] or any other model) of each zone is determined.

d) Temperature of reinforcing steel is taken as the temperature of the surrounding concrete layer.

e) Concrete in tension zone is neglected while calculating the total tensile force in the section.

f) Perfect bond between steel reinforcement and concrete is assumed since the service loads don't cause any slippage or loss of bond strength when subjected to realistic fire of approximately 1 hour duration.

\section{Methodology}

Following steps are followed to determine the residual strength of the beams subjected to fire

a) Divide the entire width of beam into slices of $5 \mathrm{~mm}$ towards the edges and $10 \mathrm{~mm}$ towards the middle of the section.

b) Using any of the temperature prediction methods, find the average temperature attained at the middle of the slice.

c) As per the temperature reached in a slice, assign the strength reduction factors for calculating the residual strength of concrete in respective slices.

d) Assign strength reduction factor for reinforcing steel as per the temperature of the reinforcement. Assume same temperature in the reinforcement as in surrounding concrete.

e) For best results, combination of temperature profile prediction of Desai's [5] Method, residual steel strength of Tao et al. [12] Model and residual concrete strength model of Eurocode 4 [8]) should be used.

f) Find the depth of Neutral Axis as explained below

i. Find the total tensile force in reinforcement

$$
F_{T}=K_{s t}^{*} A_{s t}^{*} f_{y}
$$

Where

$\mathrm{F}_{\mathrm{T}} \quad$ Total tensile force in Reinforcing steel

$\mathrm{K}_{\text {st }} \quad$ Strength reduction factor for steel after exposure to temperature $\mathrm{T}$

$\mathrm{A}_{\text {st }} \quad$ Area of steel in tension

$\mathrm{f}_{\mathrm{y}} \quad$ Yield strength of steel

ii. Find the compressive force per unit depth of the section as below

Where

$$
F_{C}=\sum_{i=1}^{n} w_{i}^{*} K_{s i}^{*} f_{c k}
$$

$\mathrm{F}_{\mathrm{c}} \quad$ Total compressive force in concrete per unit depth of section

$\mathrm{K}_{\mathrm{si}} \quad$ Strength reduction factor for concrete of $\mathrm{i}$ th slice

$\mathrm{W}_{\mathrm{i}} \quad$ Width of $\mathrm{i}^{\text {th }}$ concrete slice

$f_{c k} \quad$ Ultimate compressive strength of concrete

g) Modified Depth of NA is given by

$Y=\frac{F_{T}}{F_{C}}$

h) The moment capacity of the beam under consideration is given by

$$
M_{r}=Z^{*} F_{T}
$$

Where $Z=d-Y / 2$

\section{Test Data}

A total of 9 test results of fire damaged RC beams (exposed to fire, cooled and then tested for their residual load/moment 
capacities) from four studies were selected for evaluation of the proposed 'Actual Reduced strength Method'. The predicted moment capacities have been compared with the experimental moment capacity (tested under four point loading test condition). The details of reference beams are given in (Table 1).

Table 1: Reference beam details.

\begin{tabular}{|c|c|c|c|c|c|c|c|c|c|c|c|}
\hline \multirow{2}{*}{$\begin{array}{c}\text { Fire Parameters } \\
\qquad \mathrm{T}_{\mathrm{f}}\left({ }^{\circ} \mathrm{C}\right)\end{array}$} & \multirow[b]{2}{*}{$\mathrm{t}(\mathrm{hrs})$} & \multirow[b]{2}{*}{$\begin{array}{c}\mathrm{b} \\
(\mathrm{mm})\end{array}$} & \multirow[b]{2}{*}{$\begin{array}{c}\mathrm{D} \\
(\mathrm{mm})\end{array}$} & \multirow[b]{2}{*}{$\begin{array}{c}\mathrm{L} \\
(\mathrm{mm})\end{array}$} & \multirow[b]{2}{*}{$\begin{array}{c}\mathrm{l}_{0} \\
(\mathrm{~mm})\end{array}$} & \multirow[b]{2}{*}{$\begin{array}{c}\mathrm{c} \\
(\mathrm{mm})\end{array}$} & \multirow[b]{2}{*}{$\begin{array}{c}\mathrm{f}_{\mathrm{c}} \\
(\mathrm{MPa})\end{array}$} & \multicolumn{2}{|c|}{ Tension Reinforcement } & \multicolumn{2}{|c|}{ Compression Reinforcement } \\
\hline & & & & & & & & $\begin{array}{c}\mathrm{n}-\phi \\
(\mathrm{mm})\end{array}$ & $\mathrm{f}_{\mathrm{y}}(\mathrm{MPa})$ & $\begin{array}{c}\mathrm{n}-\phi \\
(\mathrm{mm})\end{array}$ & $\mathrm{f}_{\mathrm{y}}(\mathrm{MPa})$ \\
\hline \multicolumn{12}{|c|}{ \#\#Yuye et al. [1] } \\
\hline 1050 & 2.5 & 250 & 400 & 4000 & 1330 & 30 & 28.5 & $3-25$ & 457.5 & $2-14$ & 472.5 \\
\hline \multicolumn{12}{|c|}{ \#Kodur et al. [2] } \\
\hline 1100 & 1 & 254 & 406 & 3952 & 860 & 41 & 52.2 & 3-19 & 420 & $2-13$ & 420 \\
\hline 1100 & 1 & 254 & 406 & 3952 & 860 & 41 & 93.3 & 3-19 & 420 & $2-13$ & 420 \\
\hline 1100 & 2 & 254 & 406 & 3952 & 860 & 41 & 93.3 & 3-19 & 420 & $2-13$ & 420 \\
\hline \multicolumn{12}{|c|}{ \#\#Kumar et al. [3] } \\
\hline 1006 & 1 & 200 & 300 & 3660 & 1330 & 25 & 17 & $4-12$ & 415 & $2-10$ & 415 \\
\hline 945 & 1.5 & 200 & 300 & 3660 & 1330 & 25 & 17 & $4-12$ & 415 & $2-10$ & 415 \\
\hline \multicolumn{12}{|c|}{ \#Moetaz et al. [4] } \\
\hline 650 & 0.5 & 120 & 200 & 1800 & 600 & 20 & 20 & $2-10$ & 358.5 & $2-10$ & 235 \\
\hline 650 & 1 & 120 & 200 & 1800 & 600 & 20 & 20 & $2-10$ & 358.5 & $2-10$ & 235 \\
\hline 650 & 2 & 120 & 200 & 1800 & 600 & 20 & 20 & $2-10$ & 358.5 & $2-10$ & 235 \\
\hline
\end{tabular}

\section{Methodology for Prediction of Residual Moment Capacity using Various Methods}

Moment capacity of any RC flexural member will depend on the residual strengths of its constituents i.e. concrete and reinforcing steel and it would vary from point to point. From various residual strength models it has emerged that concrete loses most of its strength post exposure to high temperatures. It is convenient to assume with fair accuracy that the tensile strength of concrete can be totally ignored for all practical purposes. The residual compressive strength of concrete exposed to temperature $T_{f}$ $\left({ }^{\circ} \mathrm{C}\right)$ can be predicted using the constitutive models proposed in previous paragraphs. Whereas in case of reinforcing steel most of the initial strength is regained and various models proposed for residual strength can be used. Most of the models predict fair amount of recovery of tensile strength post fire exposure. Combination of various models of residual strength prediction of concrete and reinforcing steel of RC flexural elements have been studied to arrive at the best fitting combination for predicting the moment capacities. Here Experimental moment capacities of the beams tested by various researchers in literature have been picked for comparison with moment capacities using residual strength models to judge the relative performance of these models For temperature profile prediction model proposed by Desai [5] has been used for predicting the residual moment capacity of fire exposed beams. For residual strength of concrete, models proposed by Eurocode 4 [8], Chang et al. [9], Hsu et al. [10] and Xiaoyong et al. [11] have been used. For predicting the residual strength of reinforcing steel models proposed by Tao et al. [12] and Topcu et al. [13] have been used. It is pertinent to mention here that the existing models have used temperature profile prediction model as proposed by Wickstorm [14,15], concrete strength reduction model of Eurocode 4 [8] and residual strength of reinforcing steel models proposed by Tao et al. [12].

\section{Result and Discussion}

Table 2: Comparison of predicted and experimental moment capacities of proposed model with existing models.

\begin{tabular}{|c|c|c|c|c|c|c|c|c|c|c|c|c|c|c|c|}
\hline \multirow{4}{*}{$\sum_{\text {is }}^{0}$} & \multirow{4}{*}{ 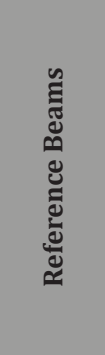 } & \multirow{4}{*}{ 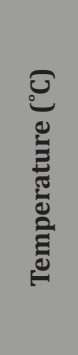 } & \multirow{4}{*}{ 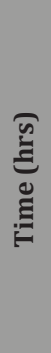 } & \multirow{4}{*}{ 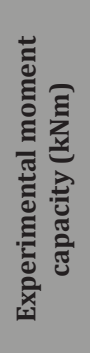 } & \multicolumn{11}{|c|}{ Predicted Moment Capacity (kNm) } \\
\hline & & & & & \multicolumn{3}{|c|}{ Existing Models } & \multicolumn{8}{|c|}{ Models Studied in this Paper } \\
\hline & & & & & \multirow{2}{*}{ 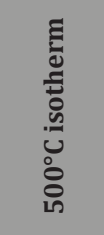 } & \multirow{2}{*}{ 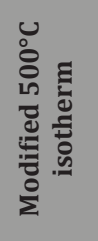 } & \multirow{2}{*}{ 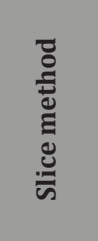 } & \multicolumn{4}{|c|}{ Steel Model:Tao et al. } & \multicolumn{4}{|c|}{ Steel Model: Topcu et al. } \\
\hline & & & & & & & & 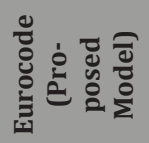 & 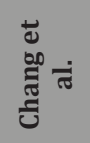 & 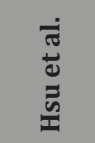 & 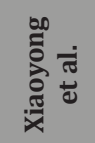 & 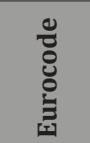 & 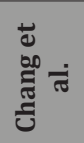 & 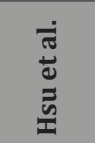 & 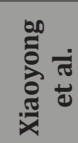 \\
\hline 1 & $\begin{array}{c}\text { Yuye et } \\
\text { al. [4] }\end{array}$ & 1050 & 2 & 167.1 & 194.27 & 179.74 & 168.03 & 165.48 & 161.2 & 155.96 & 164.89 & 91.07 & 90.08 & 88.87 & 90.93 \\
\hline
\end{tabular}




\begin{tabular}{|c|c|c|c|c|c|c|c|c|c|c|c|c|c|c|c|}
\hline \multirow{3}{*}{2} & \multirow{3}{*}{$\begin{array}{l}{ }^{* *} \text { Kodur } \\
\text { et al. [1] }\end{array}$} & 1100 & 1 & 153.6 & 118.89 & 116.69 & 113.13 & 125.02 & 110.15 & 108.78 & 110.57 & 75.29 & 73.11 & 72.55 & 75.46 \\
\hline & & 1100 & 1 & 163.59 & 119.72 & 118.14 & 114.81 & 118.02 & 115.05 & 114.28 & 115.28 & 76.34 & 75.12 & 74.8 & 76.43 \\
\hline & & 1100 & 2 & 142.31 & 113.16 & 112.01 & 105.74 & 112.95 & 108.83 & 107.77 & 108.19 & 64.56 & 63.26 & 62.92 & 64.57 \\
\hline \multirow{2}{*}{3} & \multirow{2}{*}{$\begin{array}{c}\text { Kumar } \\
{[2]}\end{array}$} & 945 & 1 & 46.5 & 43.96 & 42.4 & 40.32 & 36.99 & 34.08 & 32 & 33.89 & 11.99 & 11.69 & 11.57 & 11.95 \\
\hline & & 1006 & 1.5 & 39.3 & 40.84 & 39.23 & 36.33 & 33.77 & 28.56 & 26.74 & 26.56 & 24.89 & 21.98 & 20.98 & 23.2 \\
\hline \multirow{3}{*}{4} & \multirow{3}{*}{$\begin{array}{c}\text { Moetaz } \\
\text { et al. } \\
\text { [3] }\end{array}$} & 650 & 0.5 & 14.81 & 8.84 & 8.77 & 8.63 & 9.56 & 9 & 8.87 & 9.08 & 15.5 & 15.4 & 15.31 & 15.59 \\
\hline & & 650 & 1 & 13.54 & 8.81 & 8.73 & 8.6 & 8.8 & 8.89 & 8.76 & 8.76 & 15.01 & 14.9 & 14.82 & 15.1 \\
\hline & & 650 & 2 & 10.5 & 8.33 & 8.23 & 8.23 & 8.7 & 8.77 & 8.63 & 8.62 & 14.56 & 14.55 & 14.46 & 14.74 \\
\hline
\end{tabular}

The residual moment capacities of RC beam exposed to fire isotherm method and slice method. These predicted residual and then cooled have been predicted by using the existing models moment capacities values are compared with the experimental available, namely, $500^{\circ} \mathrm{C}$ isotherm method, modified $500^{\circ} \mathrm{C}$ results (Table 2).

Table 3: Comparison of \% Erro redicted and experimental moment capacities of proposed model with existing models.

\begin{tabular}{|c|c|c|c|c|c|c|c|c|c|c|c|c|c|c|c|}
\hline \multirow{4}{*}{$\sum_{\text {is }}^{0}$} & \multirow{4}{*}{ 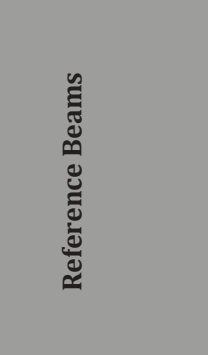 } & \multirow{4}{*}{ 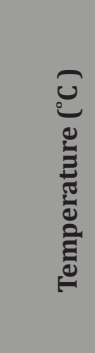 } & \multirow{4}{*}{ 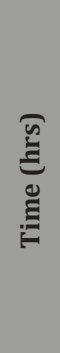 } & \multirow{4}{*}{ 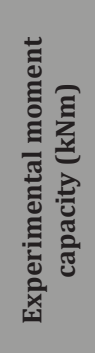 } & \multicolumn{11}{|c|}{ \% Error } \\
\hline & & & & & \multicolumn{3}{|c|}{ Existing Models } & \multicolumn{8}{|c|}{ Models Studied in this Paper } \\
\hline & & & & & \multirow{2}{*}{ 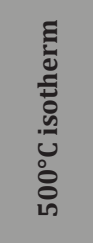 } & \multirow{2}{*}{ 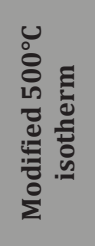 } & \multirow{2}{*}{ 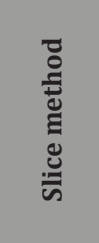 } & \multicolumn{4}{|c|}{ Steel Model: Tao } & \multicolumn{4}{|c|}{ Steel Model: Topcu } \\
\hline & & & & & & & & 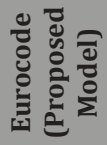 & 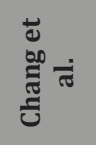 & 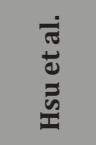 & 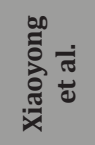 & 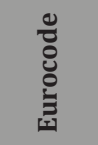 & 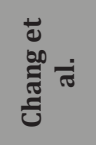 & 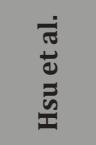 & 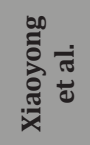 \\
\hline \multirow{2}{*}{1} & \multirow{2}{*}{ Yuye et al. [4] } & 1050 & 2 & 167.1 & 16.26 & 7.56 & 0.56 & -0.97 & -3.53 & -6.67 & -1.32 & -45.5 & -46.09 & -46.82 & -45.58 \\
\hline & & 1100 & 1 & 153.6 & -22.6 & -24.03 & -26.35 & -18.61 & -28.29 & -29.18 & -28.01 & -50.99 & -52.4 & -52.77 & -50.87 \\
\hline \multirow{3}{*}{2} & \multirow{3}{*}{ **Kodur et al. [1] } & 1100 & 1 & 163.59 & -26.82 & -27.78 & -29.82 & -27.86 & -29.67 & -30.14 & -29.53 & -53.34 & -54.08 & -54.27 & -53.28 \\
\hline & & 1100 & 2 & 142.31 & -20.48 & -21.29 & -25.7 & -20.63 & -23.52 & -24.27 & -23.98 & -54.63 & -55.55 & -55.79 & -54.63 \\
\hline & & 945 & 1 & 46.5 & -5.46 & -8.82 & -13.29 & -20.44 & -26.7 & -31.18 & -27.12 & -74.21 & -74.86 & -75.11 & -74.3 \\
\hline \multirow{2}{*}{3} & \multirow{2}{*}{ Kumar [2] } & 1006 & 1.5 & 39.3 & 3.92 & -0.18 & -7.56 & -14.07 & -27.32 & -31.96 & -32.41 & -36.67 & -44.07 & -46.63 & -40.97 \\
\hline & & 650 & 0.5 & 14.81 & -40.31 & -40.78 & -41.73 & -35.47 & -39.26 & -40.1 & -38.71 & 4.63 & 3.97 & 3.36 & 5.25 \\
\hline \multirow{2}{*}{4} & \multirow{2}{*}{ Moetaz et al. [3] } & 650 & 1 & 13.54 & -34.93 & -35.52 & -36.48 & -35 & -34.36 & -35.31 & -35.27 & 10.87 & 10.06 & 9.43 & 11.51 \\
\hline & & 650 & 2 & 10.5 & -20.67 & -21.62 & -21.62 & -17.14 & -16.51 & -17.77 & -17.89 & 38.71 & 38.54 & 37.74 & 40.36 \\
\hline
\end{tabular}

The \% Error observed in predicted moment capacities from the experimental values for various methods is shown in (Table 3).

\section{Observations}

The \% Error in Residual moment capacity observed from Table 3 for the combination of residual steel strength model of Tao and residual concrete strength model of Eurocode is ranging from $-0.97 \%$ to $-35.47 \%$ for all reference beams.

Figure 1 gives graphical Comparison of residual moment capacities of fire damaged beams obtained from best available analytical model (Slice Method) and New proposed Method with experimental results of all the reference beams.

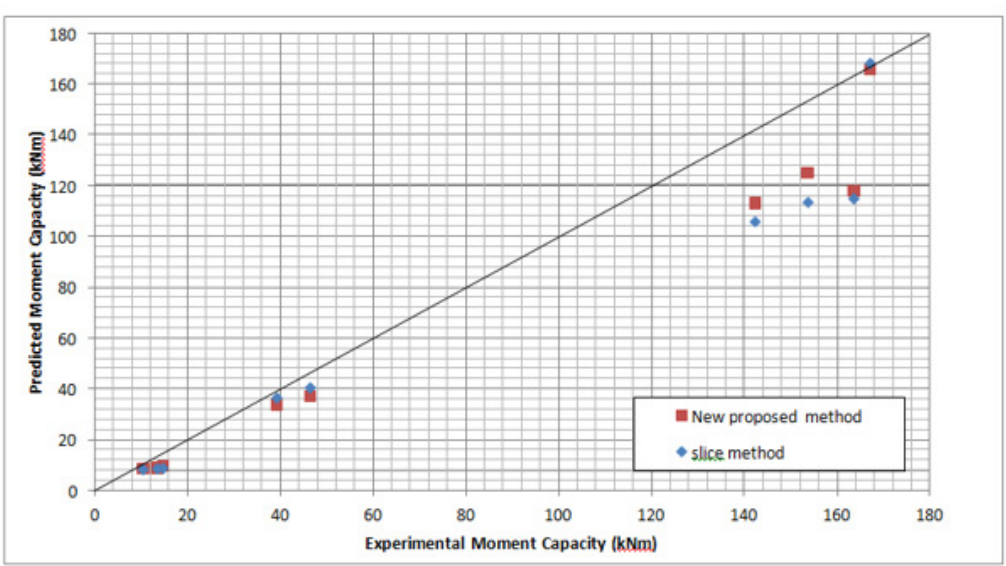

Figure 1: Experimental versus Predicted Moment capacities. 
Table 4: Comparison of \% Error Range of predicted and experimental moment capacities of proposed model with existing models.

\begin{tabular}{|c|c|c|c|c|}
\hline \multirow{2}{*}{ S No } & \multirow{2}{*}{ Model } & \multicolumn{2}{|c|}{ \% Error } & \multirow{2}{*}{ \% Error Range } \\
\cline { 3 - 4 } & Lowest & Highest & 56.57 \\
\hline 1 & 500 Isotherm & 16.26 & -40.31 & 48.35 \\
\hline 3 & Mod 500 Isotherm & 7.56 & -40.78 & 42.29 \\
\hline 4 & Slice Method & 0.56 & -41.73 & 34.5 \\
\hline
\end{tabular}

It is clear from Table 4 that new proposed 'Reduced Strength Model' gives the best predictions of the residual moment capacity after fire exposure.

All predictions of the new proposed 'Reduced Strength Model' are conservative in nature hence more suitable for assessment of residual moment capacities.

If beams of section more than $200 \mathrm{~mm} \times 120 \mathrm{~mm}$ are only considered then the \% Error range for the new proposed method with combination of residual steel strength model of Tao and residual concrete strength model of Eurocode reduces to $26.82 \%$.

\section{Conclusion}

Following conclusions emerge from the present study

a) The proposed model gives conservative results within a reasonable range of about $35 \%$ of experimental results for beams of all dimensions, though it gives best prediction for beam of section more than $200 \times 120 \mathrm{~mm}$, which normally is the case.

b) The large variation in predicted moment capacity of smaller beams can be attributed to smaller dimensions of the beams and hence more exposure to two way fire effect leading to more deterioration of strength of the reinforcing steel and concrete. The loss of bond in thinner beams also leads to reduced moment capacity which has not been incorporated in the proposed model.

c) As per the above findings the proposed model is recommended for evaluating the residual moment capacity of the beams with dimensions greater than $200 \times 120 \mathrm{~mm}$ and subjected to fire of approximately $1 \mathrm{hr}$ duration.

d) The proposed procedure is simple and can be easily programmed as has been done in the present case.

\section{Acknowledgement}

None.

\section{Conflicts of Interest}

No conflict of interest.

\section{References}

1. Kodur VKR, Dwaikat MB, Fike RS (2010) An approach for evaluating the residual strength of fire-exposed RC beams. Magazine of Concrete Research 62 (7): 479-488.

2. Kumar A (2003) Behavior of RCC beams after exposure to elevated temperatures. Journal of the Institution of Engineers (India): Civil Engineering Division 84 (3): 165-170.

3. Moetaz ME, Ragab AM, Azim AA, Elibiari S (1996) Effect of fire on flexural behavior of RC beams. Construction and Building Material 10(2): 147150 .

4. Yuye X, Wu B, Jiang M, Huang X (2012) Experimental study on residual flexural behavior of reinforced concrete beams after exposure to fire. Advanced Materials Research 457(458): 183-187.

5. Desai SB (1998) Design of reinforced concrete beams under fire exposure conditions. Magazine of Concrete Research 50 (1): 75-83.

6. Lin TD, Ellingwood B, Piet $O$ (1988) Flexural and Shear Behavior of Reinforced Concrete Beams during Fire Tests (NBSGCR-87-536). U.S. Department of Commerce National Institute for Science and Technology Center for Fire Research Gaithersburg America.

7. Wade C (1991) Method for Fire Engineering Design of Structural Concrete Beams and Floor Systems. BRANZ Technical Recommendation No. 8 Building Research Association of New Zealand Wellington New Zealand.

8. Eurocode 4, Design of composite steel and concrete structures - part 1-2: general rules structural fire design (EN 1994-1-2:2005) European Committee for Standardization. Brussels 2005.

9. Chang YF, Chen YH, Sheu MS, Yao GC (2006) Residual stress-strain relationship for concrete after exposure to high temperatures. Cement and Concrete Research 36: 1999-2005.

10. Hsu JH, Lin CS (2006) Residual bearing capabilities of fire-exposed reinforced concrete beams. International Journal of Applied Science and Engineering 4(2): 151-163

11. Xiaoyong L, Fanjie B, Dai M (2011) Residual strength for concrete after exposure to high temperatures. (Eds.): ICCIC 2011, Part II, CCIS 232, pp. 382-390

12. Tao Z, Wang XQ (2013) Stress-strain curves of structural and reinforcing steels after exposure to elevated temperatures. Journal of Materials in Civil Engineering, 25(9).

13. Topcu LB, Karakurt C (2008) Properties of reinforced concrete steel rebars exposed to high temperatures. Hindawi Publishing Corporation Research Letters in Materials Science.

14. Wickstrom U (1986) A very simple method for estimating temperatures in fire exposed structures. New Technology to Reduce Fire Losses and Costs Elsevier Applied Science London, pp. 186-194.

15. Chiang CH, Tsaib CL (2003) Time- temperature analysis of bond strength of a rebar after fire exposure. Fire Safety Journal 44 (2009): 997-1002. 